\title{
Mechanical Performance Test and Analysis of DC Charging Cable for Electric Vehicles
}

\author{
Lin Li, Zhiyong Xiao and Guiping Lu \\ Beijing Institute of Technology, ZHUHAI
}

\begin{abstract}
The mechanical performance of the cable is directly related to the electrical performance of the cable, and even affects the safety, reliability and durability of the whole charging process. Electric vehicle charging cable is different from the traditional wire and cable, which has higher requirements for the mechanical properties of the cable. In this paper, the tension test is carried out on the insulation or sheath of the cable. By observing the phenomenon of "slipping" and "end breaking" in the process of the test, the structure of the flat push collet is optimized. It can be seen from the comparative test analysis that the improved chuck mechanism has a great effect on improving the test accuracy and reliability
\end{abstract}

\section{Introduction}

With the development of electric vehicle, the performance of charging cable as a basic component plays an important role in the whole charging process[1]. The mechanical performance of the cable is directly related to the electrical performance of the cable, and even affects the safety, reliability and durability of the whole charging process. Electric vehicle charging cable is different from the traditional wire and cable, which has higher requirements for the mechanical properties of the cable. At present, China's mechanical property test standards are based on two sets of standards GB/T 2951-2008 and GB/T 17650-1998, there are few methods for the mechanical strength test of the finished cable, only a new method for swing test and extrusion test is given.

The release of relevant standards provides test methods and theoretical support for the research of mechanical properties of electric vehicle charging cable. Also, the performance index obtained from the standard test is suitable for the reference of cable performance analysis, which is the key to the excellent performance of the feedback cable. So, it is very important to verify the applicability and improvement of the standard method.

In this paper, according to "The general test method for insulating and sheathing materials of cables and optical cables", the tensile test is carried out on the insulating or sheathing materials of cables. This paper analyzes the phenomena of "slip" and "end break" in the process of experiment, optimizes the structure of flat push chuck, and improves the precision and efficiency of experiment.

\section{Mechanical property test of cable insulation}

\section{$2.1 \quad$ Specimens}

The specimens are three kinds of insulating core materials of $\mathrm{PVC} / \mathrm{C}$ insulation mixture type, at least five of which are used for mechanical property test before aging. A sufficiently long sample segment is cut from each tested insulated wire core sample, and the sampling length is required to be $100 \mathrm{~mm}$. All test pieces were stored in a cool place at room temperature $\left(23 \pm 2^{\circ}\right)$ at least to avoid the influence of aging caused by sunlight. The samples are copper conductor taken from the core samples, and the position is marked in the middle of each sample with an interval of $25 \mathrm{~mm}$ for the extender to identify the relevant position of the test.

The outer diameter and thickness were measured with optical instruments, and the contact pressure shall not exceed $0.07 \mathrm{~N} / \mathrm{mm}^{2}$. The thickness error shall be less than $0.01 \mathrm{~mm}$, and the width error shall be less than $0.04 \mathrm{~mm}$. Two sections of circular inner surface and stranded conductor are selected, and the relevant thickness data of three test pieces are shown in Table 1:

Table 1. Charging cable sample

\begin{tabular}{|c|c|c|c|}
\hline Specimen type & Blue 1 & Red 2 & Green 3 \\
\hline section profiles & $\begin{array}{c}\text { Circular } \\
\text { internal } \\
\text { surface }\end{array}$ & $\begin{array}{c}\text { Stranded } \\
\text { conductor }\end{array}$ & $\begin{array}{c}\text { Circular } \\
\text { internal } \\
\text { surface }\end{array}$ \\
\hline $\begin{array}{c}\text { thickness } \\
(\mathrm{mm})\end{array}$ & $0.895 \pm 0.01$ & $0.933 \pm 0.01$ & $0.855 \pm 0.01$ \\
\hline $\begin{array}{c}\text { outer diameter } \\
(\mathrm{mm})\end{array}$ & $4.288 \pm 0.04$ & $3.836 \pm 0.04$ & $3.695 \pm 0.04$ \\
\hline
\end{tabular}




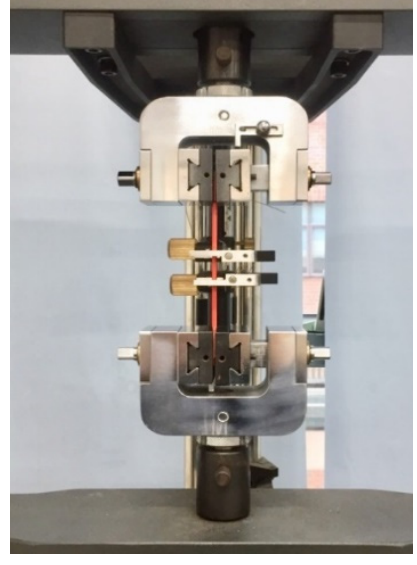

Fig.1 Specimen mounting diagram

This test is based on the electronic universal testing machine (model utm4204) developed by Shenzhen sanshizong company. According to the standard, when the non self tightening collet is used to clamp the test piece, the total spacing between the control collets is about $85 \mathrm{~mm}$, and then the extensometer is evenly clamped on both ends of the test piece to ensure the spacing is $25 \mathrm{~mm}$. The clamping test piece was centered between two chucks as much as possible. The effect of clamping the test piece before the test is as shown in Figure 1.

\subsection{Analysis of test data}

The extensometer transmits the real-time tension value collected to the industrial computer, and extracts the maximum tension after processing. At the same time, the distance between the two marked lines is measured on the same test piece.

(1) Calculation formula for tensile strength[2]:

$$
\sigma=\frac{F_{b}}{A}
$$

$\boldsymbol{F}_{\mathrm{b}}$ - Maximum tension, Unit: Newton (N), Measure according to the standard and round to 2 decimal places. A - Cross section area, Unit: Square millimeter $\left(\mathrm{mm}^{2}\right)$, Measure according to the standard and round to 2 decimal places.

(2) Calculation formula of elongation at break[2]:

$$
\varepsilon_{\mathrm{t}}=\frac{L_{2}-L_{1}}{L_{1}} \times 100 \%
$$

$\boldsymbol{L}_{1}$ ——Distance between marker lines before stretching, Unit:millimeter(mm). Measure according to the standard and round to 2 decimal places.

$\boldsymbol{L}_{2}$ - Distance between marker lines after stretching, Unit:millimeter(mm). Measure according to the standard and round to 2 decimal places.

According to Eqs (1) and (2), relevant data collected by Material Test 4.1 platform was substituted to obtain relevant data. The relevant data of three types of insulation test pieces of blue, red and green are arranged as shown in Table 2 .

Table 2. Data sheet of tensile test

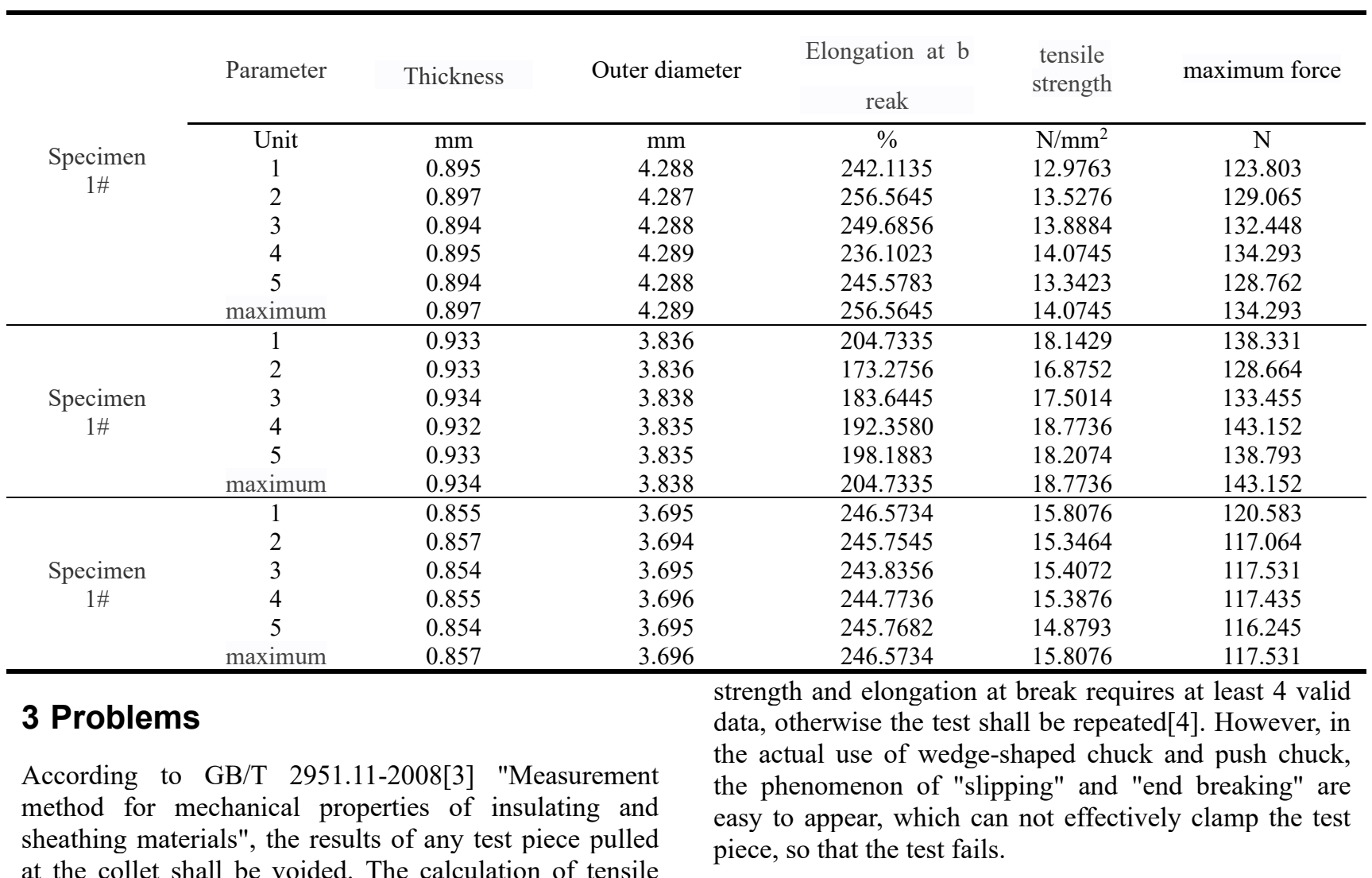


"Slip": refers to the sliding between the test piece and the bayonet, even falling out of the block at one end (as shown in Fig.2). This phenomenon causes the test to fail and the test piece to be scrapped. The residual condition is shown in Fig.4 for specimens numbered "1", "8" and "9". This phenomenon often occurs in the second half of the test, when the specimen has undergone significant plastic deformation.

"End break": means that the test specimen is pulled off from the flush end of the collet at one end in the early stage of the test (as shown in Fig.3). In this case, the test results of any test specimen are invalid. As shown in the test pieces with serial numbers "2" to "7" in Figure 3.14, the test pieces did not undergo stretch whitening, that is, the test pieces were scrapped before they were still in the elastic stage or the yield stage.

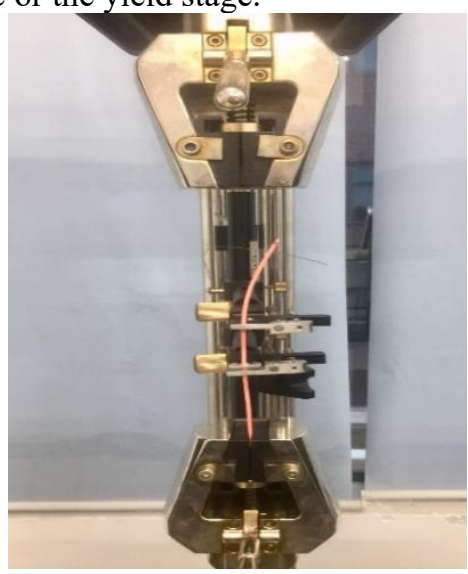

Fig.2 Failure figure of "slip"

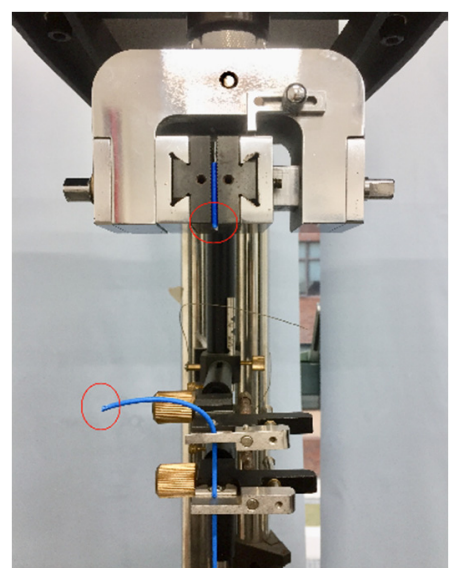

Fig.3 Failure figure of "end break"
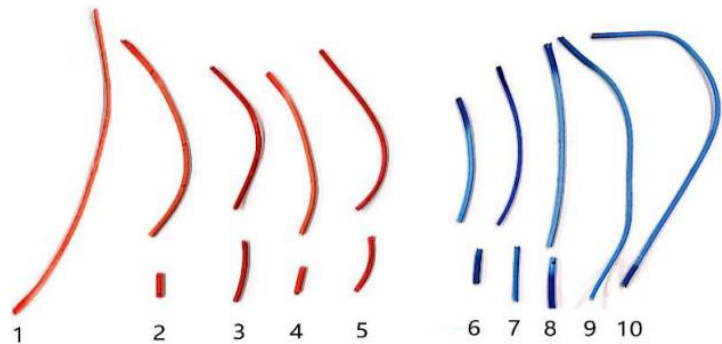

From the force-displacement curve obtained in the experiment, it can be seen that the force displacement curve presented by each sample is relatively discrete. Combined with the displacement of the abscissa and the force data of the ordinate, it can be judged that the failure test process is extremely unstable.

In the case of "end breaking", the curve will soon fall back at a smaller displacement. At the same time, the failure phenomenon of "end breaking" in two stages can be judged by the radian when falling back. In the "elastic stage" fracture, the curve fall back radian is large. In this stage, except the ductile fracture can not be recovered, the load can be recovered after withdrawing, which mainly occurs in the displacement of $30 \mathrm{~mm}$. During the "plastic stage" fracture, the curve fall back radian is small. In this stage, the specimen has undergone elastic-plastic deformation. After the load is removed, part of the curve can be recovered, mainly distributed between $83 \mathrm{~mm}$ and $126 \mathrm{~mm}$ displacement. This two stages can not reflect the real performance of the material.

When "slip" occurs, there is no difference between the curve in the initial and intermediate stages, that is, it can smoothly go through "elastic stage" and "plastic stage". However, with the increase of tensile load, the specimen began to slide between the clamps, specifically at the displacement of $111 \mathrm{~mm}$, the curve had obvious fluctuations.

So when the test piece appears "slip" and "end trimming" phenomenon, the degree of dispersion of the tensile curve generated by the feedback is large, which brings great error to the test results, and the real mechanical properties of the material can not be tested.

\section{Improvement of test chuck}

\subsection{Comparison of clamping effects}

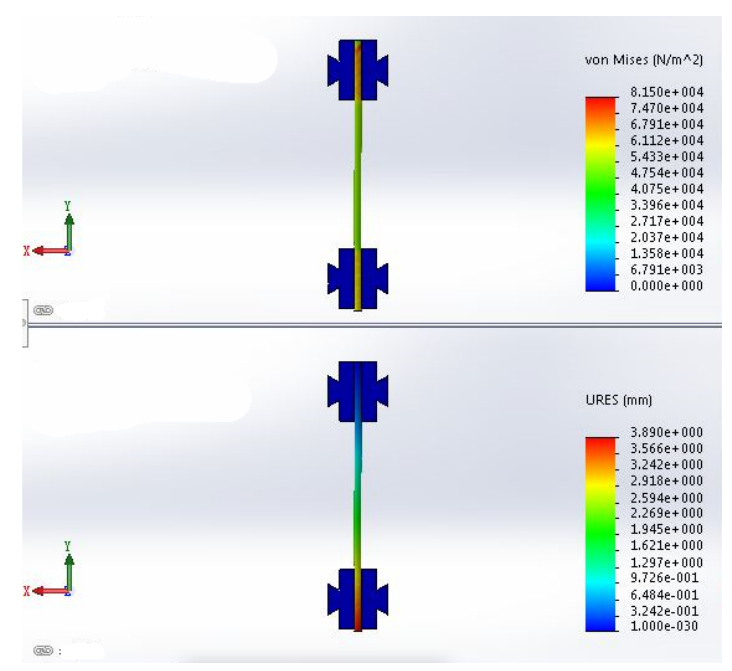

Fig.4 Failure specimen chart 


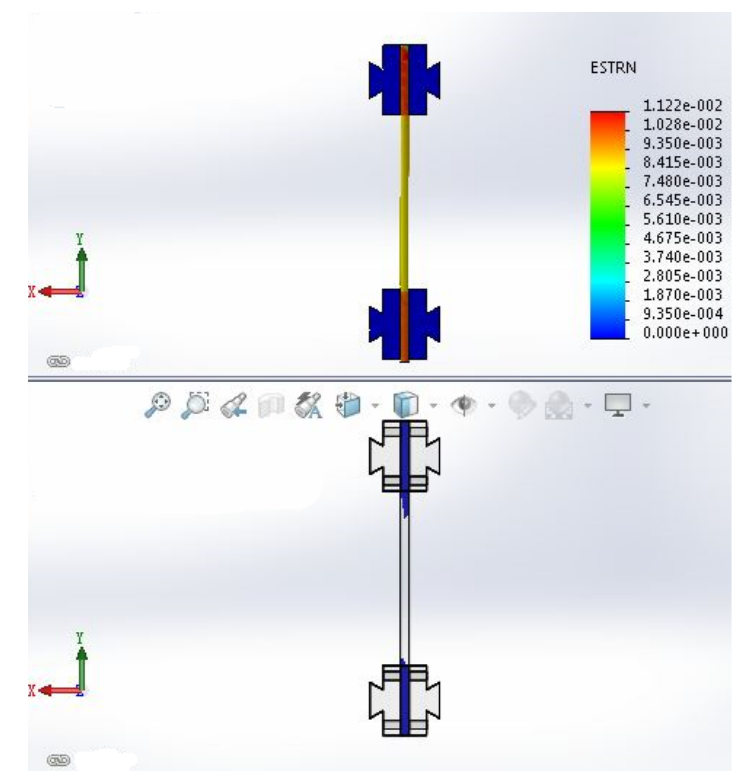

Fig.5 FEM diagram of direct clamping

Read the relevant literature and learn that there is another way of winding clamping [5-7]. Use SolidWorks software to carry out three-dimensional modeling of the main structure and import it into the simulation finite element analysis plug-in to simulate two kinds of clamping effects, as shown in Fig. 5 and Fig.6.

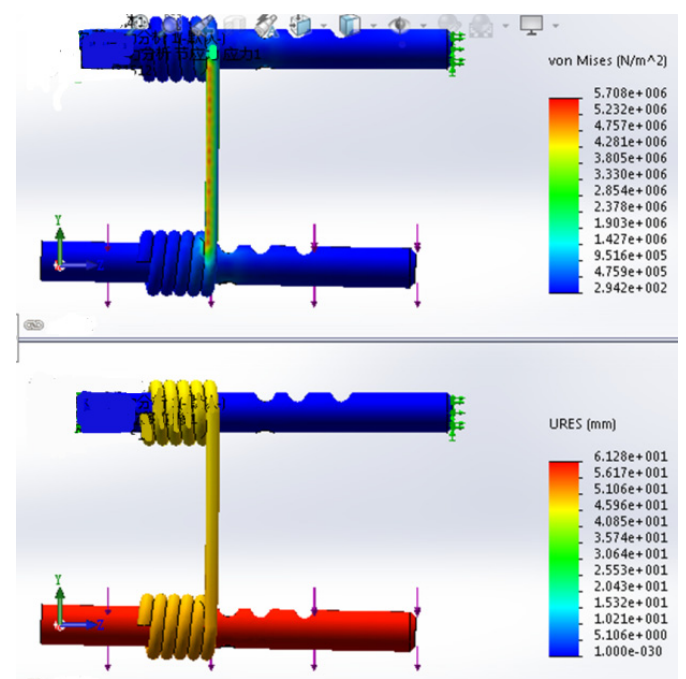

Fig.6 FEA diagram of winding clamping

Through theoretical and finite element simulation analysis, the problem of stress concentration caused by direct clamping can be avoided by winding the test piece on the support rod for clamping, so as to avoid the phenomenon of "end breaking" caused by extrusion deformation. In order to verify the feasibility of the winding clamping method, an auxiliary winding clamp was made for testing.

\subsection{Design of Clamping heads}

As shown in Fig. 7, it is a schematic diagram of a new type of winding chuck given in this design. The main structure of the chuck is divided into upper and lower parts according to its function. The upper part is the clamping and alignment function structure, mainly composed of plum handle, rotatable support rod with centering hole and bolt. The lower part is the pre tightening and positioning function structure, mainly composed of guide rod, spring, clamp block and bayonet.

As shown in Fig. 8, it is a new type of chuck produced by trial production. The main material is \#45 steel. According to the method given in the standard, the test is carried out on UTM4204 electronic universal testing machine, and the control test is carried out with the flat push type chuck. All the test pieces used are a batch of insulating materials of the same model and specification. The only difference is that the length of the test piece used for the new chuck is $200 \mathrm{~mm}$, not $100 \mathrm{~mm}$ as specified in the standard.

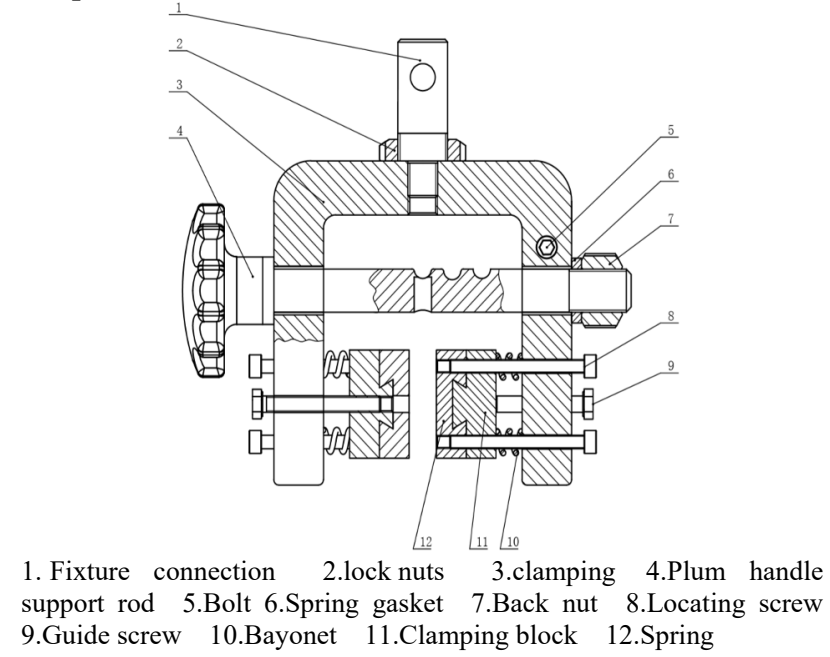

Fig. 7 Structure diagram of winding collet

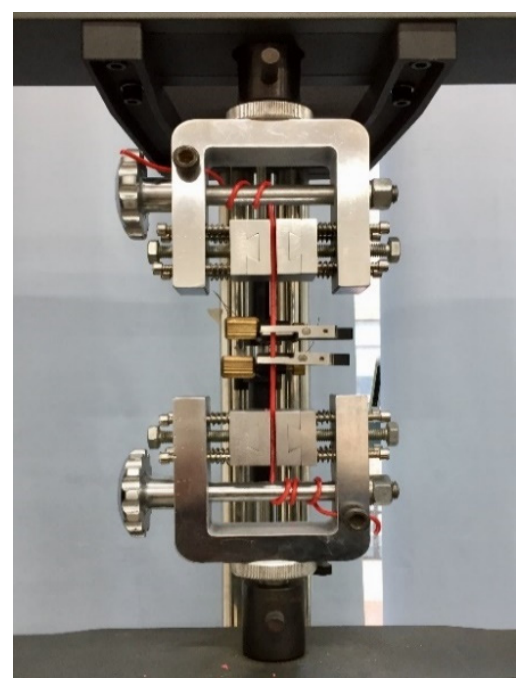

Fig.8 Winding collet prototype 


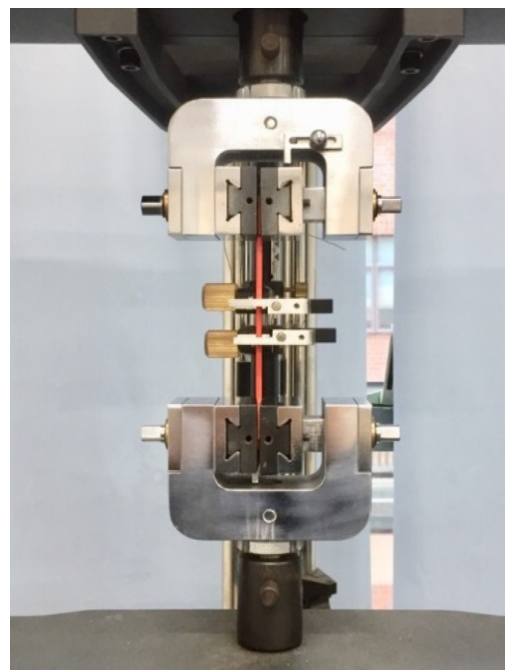

Fig.9 Horizontal pushing clamp

Table 3. Experiments 'Data Comparison

\begin{tabular}{cccc|cccc}
\hline & \multicolumn{3}{c|}{ Horizontal pushing clamp } & \multicolumn{3}{c}{ New clamp } \\
\hline $\begin{array}{c}\text { Parame- } \\
\text { ter }\end{array}$ & $\begin{array}{c}\text { Elongation at } \\
\text { break }\end{array}$ & $\begin{array}{c}\text { Tensile } \\
\text { strength }\end{array}$ & $\begin{array}{c}\text { maximum } \\
\text { force }\end{array}$ & $\begin{array}{c}\text { Parame- } \\
\text { ter }\end{array}$ & $\begin{array}{c}\text { Elongation at } \\
\text { break }\end{array}$ & $\begin{array}{c}\text { Tensile } \\
\text { strength }\end{array}$ & $\begin{array}{c}\text { maximum } \\
\text { force }\end{array}$ \\
\hline Unit & $\%$ & $\mathrm{KgF} / \mathrm{cm}^{2}$ & $\mathrm{~N}$ & Unit & $\%$ & $\mathrm{KgF} / \mathrm{cm}^{2}$ & $\mathrm{~N}$ \\
1 & 0.0000 & 12.3738 & 86.539 & 6 & 276.9431 & 15.8526 & 90.361 \\
2 & 262.9045 & 14.8970 & 88.608 & 7 & 278.1683 & 15.3737 & 89.590 \\
3 & 111.4672 & 8.9436 & 76.315 & 8 & 277.8935 & 16.5961 & 92.753 \\
4 & 265.7580 & 16.5115 & 92.747 & 9 & 277.9045 & 16.1270 & 91.608 \\
5 & 274.5584 & 16.3115 & 92.596 & 10 & 278.8945 & 16.8544 & 93.114 \\
maximum & 274.7580 & 16.5115 & 92.747 & maximum & 278.0935 & 16.8544 & 93.114 \\
\hline
\end{tabular}

In order to determine whether the new collet has an impact on the test results, the extracted relevant data are sorted out as shown in table 3 below.

According to the data in the table above, when the flat push chuck test was used, the "slip" phenomenon occurred in the specimen with the serial number "1", which showed that the curve fluctuated in the later section and then dropped. The specimen with serial number "3" had a "end trimming" phenomenon, showing that the curve suddenly changed abruptly during the rise. In contrast, the use of the new chucks has ensured the normal conduct of the test. Therefore, the curves of the failed test pieces are excluded for analysis, and the remaining 8 tensile curves are concentrated, which is in accordance with the characteristic curve of the insulating material.

(1)From the perspective of the maximum tensile force, except for the data of the failed test pieces with serial numbers " 1 " and " 3 ", the rest of the data are concentrated between $88 \mathrm{~N}-93 \mathrm{~N}$. It can be considered that the tension value obtained by using the new type of collet test is more stable than that of the flat collet.

$$
\begin{gathered}
{\sigma_{\mathrm{Old}}}^{2}=\frac{\Sigma(X-\mu)^{2}}{\boldsymbol{N}}=3.6842 \\
{\sigma_{\mathrm{New}}}^{2}=\frac{\Sigma(X-\mu)^{2}}{\boldsymbol{N}}=1.83 \\
\boldsymbol{\sigma}_{\mathrm{Old}}{ }^{2}>\boldsymbol{\sigma}_{\mathrm{New}}{ }^{2}
\end{gathered}
$$

(2)From the perspective of tensile strength, there is little difference in the data obtained from the successful

test of two collets.

(3)In terms of elongation at break, the value obtained by using the new collet is larger than that by using the flat collet. This is because the specimen selected for the new chuck is $200 \mathrm{~mm}$, and with the increase of material modulus, it can naturally withstand a longer stretching distance during the stretching process.

\section{Conclusion}

It is verified by the prototype that the new type of winding collet can facilitate the correct clamping of the test piece, ensure that the stress of the test piece is even during the test process, and solve the problems of "slip" and "end breaking". The measured data is stable and has little difference with the value measured when using the specified chuck, which can ensure the accuracy and reliability of the test results. Moreover, it improves the success rate and efficiency of the test, and achieves the test results required by the standard. It provides an improved method and reference for selecting mechanical chuck to clamp the soft material samples of cable insulation and sheath for tensile test. Since the new collet is a non-standard part, the corresponding test method should be improved simultaneously for the use of the collet.

\section{References}

1. Tian Chaohe, Lu Chengyu, et.:Standardization 
analysis of electric vehicle charging cable. Electrical industry (11), 60-63(2013).

2. Su Delin.:Mechanical properties of engineering materials. Mechanical Industry Press. Beijing(2016).

3. GB/T 2951.11-2008.: General test methods for insulating and sheathing materials of cables and optical cables. China Standards Press. Beijing(2008).

4. Liu lang, Chen Ming, Guo Chunmei, et.: Study on the fracture of PVC/MBS blends. Synthetic resin and plastics 26(03), 26-28(2009).

5. Zhang Xu.: Research on fault simulation method of submarine high voltage photoelectric composite cable. North China Electric Power University, (2013).

6. Cao Yiyan.: Simulation of tensile mechanical behavior of high strength composite cable. Material development and Application32(05), 47-52(2017).

7. Li Linshu, Yang Jie, Hu Yongle,et.: FEM and Simulation of bending of DC charging cable of electric vehicle. Wire and cable(02),12-15 (2019). 